\title{
Entre a mediação e a exposição - sobre o idioleto de Walter Benjamin
}

\section{Georg Otte, UFMG}

Resumo: Quando Benjamin, na primeira frase do prefácio de Origem do drama barroco alemão, atribui um lugar central à questão da Darstellung (exposição, apresentação), ele se distancia do discurso acadêmico tradicional, baseado no uso sistemático de conceitos e seu papel mediador. Partindo da crítica de Jeanne Marie Gagnebin à tradução de Darstellung como "representação" e também dos questionamentos de Adorno, procuramos desenvolver uma distinção básica entre a mediação (Vermittlung) e a exposição (Darstellung) como duas opções distintas do discurso filosófico.

Palavras-chave: mediação; apresentação; representação.

Em uma das suas palestras sobre Walter Benjamin, Jeanne Marie Gagnebin questionou, com muita ênfase, a tradução do termo Darstellung como "representação" na edição brasileira de Origem do drama barroco alemão. ${ }^{1}$ Aparentemente uma questão secundária, um detalhe de tradução, a crítica, na verdade, toca numa questão fundamental em Benjamin, como ela mostrou também em um trabalho dedicado exclusivamente a essa questão. ${ }^{2} \mathrm{O}$ próprio Benjamin não deixa dúvidas de que se trata de uma questão de primeira ordem, uma vez que a tematiza logo na primeira frase do "Prefácio epistemológico", no qual declara, no habitual tom apodítico: "É próprio da escrita filosófica confrontar-se, cada vez de novo, com a questão da exposição [Darstellung]."

Uma vez que esse "Prefácio" faz parte da escrita filosófica, seria incoerente se o próprio Benjamin não desse o exemplo: o próprio tom apodítico, propagado explicitamente no texto, faz parte da exposição de suas ideias: Benjamin não argumenta de forma linear, mas expõe suas ideias acumulando afirmações que muitas vezes não apresentam uma conexão sintática entre si. Fazer afirmações, em alemão, Behauptungen aufstellen, ou seja, poderíamos ampliar ainda mais o campo lexical do verbo stellen ("colocar em pé"), de forma semelhante a J. M. Gagnebin no referido artigo, quando compara darstellen com o verbo ausstellen, o expor no contexto de uma exposição de arte. O discurso de Benjamin, portanto, é da ordem da verticalidade, no sentido de não se preocupar em providenciar ao leitor as ligações "horizontais" entre cada afirmação, despreocupação esta que se evidencia até no plano gramatical, pois dificilmente o leitor encontra conjunções de caráter causal ou final. $^{4}$

O tom apodítico - ou até mesmo lacônico - culmina na afirmação "Método é caminho indireto, é desvio", (Methode ist Umweg.). Como aponta J. M. Gagnebin, recorrendo a uma distinção feita por Diógenes Laércio, Benjamin se insere na tradição daqueles que "mostram" seu pensamento através da própria ordenação (exposição) retórica dos seus pensamentos, diferentemente da tradição dos "pesquisadores" e sua argumentação discursiva. ${ }^{6}$ Podemos reforçar essa distinção 
citando um dos fragmentos mais conhecidos das Passagens, no qual Benjamin comenta o procedimento utilizado em seu opus magnum: "Não tenho nada a dizer. Somente a mostrar." 7 A forma do fragmento, que "expõe" ainda mais o caráter nãolinear da escrita benjaminiana, se define, neste fragmento específico, como montagem, a irmã moderna, por assim dizer, do mosaico medieval, que serve de modelo para Benjamin no "Prefácio". Além do caráter imagético de ambos, que, por si só, reforça seu aspecto "expositivo", tanto a montagem quanto o mosaico fogem do risco de qualquer continuidade "horizontal" pela sua própria fragmentação.

Conforme assinalado por J. M. Gagnebin, a tradução de Darstellung por "representação" pode até ser adequada em outros contextos, mas não corresponde ao uso específico de Benjamin. Diversos dicionários do português e de outras línguas românicas fornecem, como primeira opção de tradução o termo "representação", mas, como Adorno demonstra em seu famoso "Ensaio como forma" (também citado por Gagnebin), o dicionário é uma ferramenta pouco útil para quem se move em território estrangeiro, onde o significado das palavras é conquistado exatamente pelo uso específico que as pessoas fazem delas. O professor de línguas estrangeiras sabe que o aluno iniciante que tenta escrever um texto em língua estrangeira exclusivamente com base no dicionário, ou seja, servindo-se do significado genérico das palavras, costuma produzir um texto incompreensível.

Ler Benjamin pela primeira vez é como mover-se em território estrangeiro. Os "conceitos de Benjamin" " não são os nossos conceitos, isto é, não correspondem às definições genéricas que constam nos diversos dicionários, mas ganham um significado próprio pelo uso que Benjamin faz delas em seus textos. Basta lembrar o caso da Erfahrung (experiência), que, como Darstellung, é um termo utilizado com grande frequência no alemão padrão, mas, pelo uso que Benjamin faz dele no ensaio "O narrador" e nos textos sobre Baudelaire, ganhou um significado restrito nos seus textos. É de se perguntar, portanto, se os conceitos de Benjamin são mesmo conceitos, pois, quando ganham um significado particular na obra do pensador, perdem ao mesmo tempo sua condição fundamental de conceito, a saber, sua validade semântica (supostamente) universal e, consequentemente, seu valor comunicativo. Restringindo o conceito, isto é, a palavra que o designa a um significado particular, Benjamin, sem fornecer uma nova definição, sacrifica o seu sentido universal - o que explica as dificuldades que o leitor de Benjamin enfrenta ao ler seus textos e lhe valeu o rótulo de "autor difícil".

Nos trabalhos sobre Baudelaire, Benjamin opõe o conceito de Erfahrung àquele de Erlebnis ("vivência"), uma oposição que delimita melhor o uso específico a ele atribuído, sendo que essa oposição é associada ainda a uma distinção histórica, pela qual a "experiência" seria da ordem da pré-modernidade, enquanto a "vivência" principalmente aquela do "choque" - seria um fenômeno próprio da modernidade. Se essa distinção permite uma compreensão melhor da "estrutura" do pensamento benjaminiano, ela evidencia ao mesmo tempo sua recusa de participar do debate acadêmico da época. Assim, Benjamin menciona, em "Sobre alguns motivos em Baudelaire", o livro de Dilthey, Das Erlebnis und die Dichtung (A vivência e a literatura), mas não se refere a esse livro quando, apenas algumas páginas depois, ensaia sua definição dos termos Erfahrung e Erlebnis. Além de não aceitar o valor universal dos conceitos, Benjamin, por assim dizer, "vira as costas" para o debate acadêmico da época e para o uso que outros autores fazem do mesmo termo. Mesmo concedendo que esse "valor universal" sempre passa por restrições em qualquer contexto concreto, inclusive no pensamento de Dilthey, cabe observar que Benjamin

Cadernos Benjaminianos, Número especial, Belo Horizonte, 2013, página 89-99 
é mais exigente com o leitor ao desenvolver seu discurso idiossincrático, isto é, seu idioleto.

Cabe ressaltar que não faltou esforço, por parte de Benjamin, de se submeter aos rituais acadêmicos: depois da recusa do seu primeiro texto sobre Baudelaire pelos membros do Instituto de Pesquisas Sociais, principalmente por Horkheimer e Adorno, Benjamin se esforçou a participar das discussões da época, sobretudo dialogando com aqueles autores que se tornaram as grandes inspirações do Instituto, a saber, Freud e Marx. No entanto, depois de utilizar alguns conceitos de Freud e de seu discípulo Theodor Reik e depois de falar brevemente sobre "traços mnenômicos" (Gedächtnisspuren), a defesa contra os estímulos (Reizschutz) e o rompimento dessa proteção no trauma, Benjamin passa a discutir os conceitos "memória voluntária" e "memória involuntária" em Proust e a defesa contra os choques (Chockabwehr) em Baudelaire. Se o aumento das notas de rodapé também pode sugerir um gesto acadêmico, elas não deixam dúvida quanto à preferência de Benjamin por autores literários como Poe, Heine, Börne, Hoffmann e Valéry - em detrimento dos teóricos. No entanto, mesmo com a diminuição das referências aos teóricos, Benjamin não chega a ignorar Freud, como no caso de Dilthey. Conforme Sigrid Weigel, o número reduzido das referências explícitas a Freud se encontra numa relação recíproca aos "vestígios das figuras de pensamento de Freud" na obra de Benjamin como um todo. ${ }^{9}$

Se, na passagem da primeira versão para a segunda, há uma diminuição nítida das referências a Marx, tal fato não se deve apenas à preferência pelos autores literários, mas também às objeções de Adorno ${ }^{10}$ contra um uso um tanto peculiar dos conceitos marxistas por parte de Benjamin. Além de "individualizar" conceitos do uso padrão como "experiência" e "vivência", Benjamin se permitiria um uso muito particular de termos teoricamente bem delimitados como no caso dos conceitos marxistas, causando assim certo incômodo em Adorno e seus colegas do Instituto. Em sua carta, porém, Adorno não questiona diretamente o uso desses conceitos, mas a falta de "mediação" (Vermittlung) tanto entre a superestrutura e a infraestrutura, quanto entre a teoria e a prática, e, principalmente, entre a "exposição [Darstellung] admiradora da mera facticidade" e o "processo como um todo [Gesamtprozeß]" em geral. $^{11}$

Coincidência ou não, é apenas uma das ironias na relação entre Benjamin e Adorno que este último considere a exposição, a Darstellung dos fatos, como o grande defeito do primeiro texto sobre Baudelaire, sendo que Benjamin a defende, na abertura do seu "Prefácio", como princípio primordial da escrita filosófica. Cabe lembrar, ainda, que Adorno, em 1932, ainda na Universidade de Frankfurt, havia ministrado - sem informar Benjamin sobre isso - um seminário sobre a Origem do drama barroco alemão, sabendo muito bem do lugar crucial que Benjamin havia atribuído à questão da Darstellung .

Quando cita Freud na segunda versão, Benjamin parece ter tomado um novo impulso para encontrar a "mediação" entre uma abordagem teórica amplamente aceita, a psicanálise, e a realidade da metrópole moderna em Baudelaire, e para corresponder, com esse procedimento, às expectativas de Adorno. Entretanto, parece ser outra ironia na história dessa amizade conturbada quando Adorno, apesar de sua reação "entusiasta"12 à segunda versão, questiona logo o uso dos conceitos freudianos por Benjamin, questionando ao mesmo tempo a capacidade de Benjamin de lidar com qualquer teoria em geral. E não soa menos irônico quando Adorno, ainda na mesma carta, elogia o desenvolvimento de uma "teoria do jogador [de

Cadernos Benjaminianos, Número especial, Belo Horizonte, 2013, página 89-99 
azar]" como um dos pontos culminantes da nova versão, mesmo se esse tópico dificilmente mereça ser chamado de "teoria", uma vez que Benjamin se limita a aproximar dois âmbitos sociais distantes sem recorrer a qualquer arcabouço teórico. Quando compara o jogador de azar com o operário na máquina, Benjamin não se preocupa em integrar essa comparação no "processo integral", cobrado por Adorno, mas a baseia unicamente no fenômeno do choque ao qual tanto o jogador quanto o operário estariam expostos. Sem se valer de qualquer mediação teórica, Benjamin compara o jogador, que não trabalha, ao operário obrigado a trabalhar em condições extremamente precárias. Ao invés de se valer das categorias marxistas, Benjamin os aproxima dos fenômenos sociais a partir de um critério estético, isto é, da percepção do "choque" que marcaria tanto os movimentos físicos do jogador quanto aqueles do trabalhador. Mais uma vez, Benjamin coloca - ou "expõe" - uma figura ao lado da outra com base numa analogia que já havia utilizado no início da primeira versão, quando aproximou Napoleão III à figura do conspirador $^{13}$, ou seja, duas figuras politicamente opostas. Benjamin, entretanto, passa por cima dessa adversidade política e social para unir ambos com base na imprevisibilidade de suas ações. A comparação é ampliada pela introdução de uma terceira figura, isto é, do próprio Baudelaire e seus movimentos abruptos, ou seja, mais uma vez a exposição da aparência física serve de ponto de partida para aproximar tipos sociais opostos. Reunindo as características do flâneur e do dandy, Baudelaire era muito mais um ator, um Darsteller do que representante (o termo alemão seria Vertreter) de uma classe. No lugar da representação social, Benjamin oferece ao leitor tipos alegóricos marcados pelos choques da modernidade. Em última instância, a segunda versão do texto sobre Baudelaire também não representa um avanço quanto à conceituação teórica, e a reação entusiasta de Adorno parece se dever mais ao peso na consciência diante sua "insistência maçante" (nörgelnden Insistenz) ${ }^{14}$ do que a uma efetiva mudança de postura de Benjamin ao lidar com questões teóricas, uma vez que tal mudança, na verdade, não aconteceu.

Há ainda outra ironia no fato de Adorno, em sua crítica à primeira versão do trabalho sobre Baudelaire, recorrer a elementos do "Prefácio epistemológico", criticando um texto de Benjamin com base em outro, anterior: no "Prefácio", Benjamin já havia declarado que a exposição (Darstellung) das ideias consistiria em um “... permanente retorno aos fenômenos, cada vez mais abrangente e mais intenso, graças ao qual eles em nenhum momento correm o risco de permanecer meros objetos de um assombro difuso [Gegenstände eines trüben Staunens zu bleiben], contanto que sua representação [Darstellung] seja ao mesmo tempo a das idéias, pois com isso eles se salvam em sua particularidade.“15 Quando Adorno, em sua recusa de publicar o primeiro texto sobre Baudelaire, fala na "exposição assombrosa da mera facticidade" (staunende Darstellung der bloßen Faktizität), ele sabia muito bem que a Darstellung, pelas explanações do próprio Benjamin, era muito mais do que uma enumeração positivista dos fatos. É significativo que Adorno não apenas usa o termo Darstellung contra as verdadeiras intenções de Benjamin, das quais ele tinha conhecimento, mas ainda usa o verbo staunen numa função que chega a ser ofensiva (algo como "olhar embasbacado"). Como se pode ver, Benjamin, no "Prefácio", havia usado o mesmo verbo, isto é, sua forma substantivada (Staunen), exatamente para dizer que não se trata disso. Muito pelo contrário, a "positividade condensada" (gedrängte Positivität ${ }^{16}$ ) exigida por Benjamin nada tem a ver com a "mera facticidade", mas é a condição indispensável para uma exposição monadológica da ideia. Cabe ressaltar, nesse contexto, a importância que Benjamin

Cadernos Benjaminianos, Número especial, Belo Horizonte, 2013, página 89-99 
atribui constantemente a formações imagéticas para sustentar sua defesa da Darstellung:

A idéia é mônada - isto significa, em suma, que cada idéia contém a imagem do mundo. A representação [Darstellung] da idéia impõe como tarefa, portanto, nada menos que a descrição dessa imagem abreviada do mundo [dieses Bild der Welt in seiner Verkürzung zu zeichnen ${ }^{17}{ }^{18}$

Mas parece que era também essa condensação - ou "abreviação" - que levou Adorno a cobrar a mediação necessária, apesar da característica da mônada de também expor a totalidade. Essa totalidade monadológica, entretanto, se baseia na percepção sensorial do mundo físico e, assim, no registro de analogias esteticamente fundamentadas, de maneira que tem pouco a ver com o "processo integral" (Gesamtprozess) de inspiração hegeliano-marxista e sua cronologia. Benjamin, defendendo a interrupção do próprio caráter processual da realidade, apenas se interessa por esse processo na medida em que pode ser interrompido.

Como já foi apontado, a epistemologia de Benjamin - ou melhor: a crítica à epistemologia (Erkenntniskritik) predominante da época - exige muito do leitor e não é por acaso que as dificuldades de compreensão aumentam quando Benjamin fala da mediação operada pelo conceito, como na passagem a seguir:

Graças a seu papel mediador, os conceitos permitem aos fenômenos participarem do Ser das idéias. Esse mesmo papel mediador [Vermittlerrolle] torna-os aptos para a outra tarefa da filosofia, igualmente primordial: a representação [Darstellung] das idéias. A redenção dos fenômenos por meio das idéias se efetua ao mesmo tempo que a representação [Darstellung] das idéias por meio da empiria. Pois elas não se representam [darstellen] em si mesmas, mas unicamente através de um ordenamento de elementos materiais no conceito, de uma configuração desses elementos. ${ }^{19}$

Por mais obscuro que seja o "papel mediador" do conceito em Benjamin, podemos ter certeza que ele não visa a abstração conceitual no sentido tradicional do termo e muito menos a dedução de conceitos precedentes. E quando se trata da exposição das ideias "por meio da empiria", isto é, por meio da configuração de elementos materiais, o leitor acaba se perguntando por que Benjamin ainda insiste na necessidade de conceitos, uma vez que as ideias podem e devem ser expostas (dargestellt) de forma imediata, isto é, sem uma instância mediadora. Se a ideia, por sua vez, pertence a "uma esfera fundamentalmente distinta daquela em que estão os objetos que ela apreende" ${ }^{20}$, não é mais questão de mediação, mas de exposição, tal como Benjamin a postula na primeira frase do Prefácio. Parece que Benjamin não ousou abandonar por completo a categoria do conceito enquanto mediador lógico, procurando ao mesmo tempo conciliar conceito e imagem, isto é, mediação e exposição. Resta uma sensação de ambiguidade, que só aumenta quando, no original alemão, utiliza, ainda na mesma página, o termo Repräsentation ${ }^{21}$ como sinônimo de Darstellung, ou seja, além se permitir o uso particular de determinados conceitos, falta mesmo rigor nesse uso particular.

Se o "papel mediador" dos conceitos não é ambíguo em Benjamin, sua aversão às deduções e induções como parte de um processo sucessivo e linear de reflexão não

Cadernos Benjaminianos, Número especial, Belo Horizonte, 2013, página 89-99 
deixa dúvidas quanto à sua preferência pela “contemplação não-intencional", também destacada por Gagnebin no referido artigo. Trata-se de substituir a progressão incessante, que "tira o fôlego", pela respiração meditativa e contemplativa para se aprofundar, via contemplação, no objeto:

Incansável, o pensamento começa sempre de novo, e volta sempre, minuciosamente, às próprias coisas. Esse fôlego infatigável é a mais autêntica forma de ser da contemplação. Pois ao considerar um mesmo objeto nos vários estratos de uma significação, ela recebe ao mesmo tempo um estímulo para o recomeço perpétuo e uma justificação para a intermitência do seu ritmo. ${ }^{22}$

A escrita filosófica que Benjamin defende nas primeiras páginas do "Prefácio", visa substituir a progressão horizontal pelo aprofundamento vertical - uma distinção que Erich Auerbach utilizou ao diferenciar a escrita bíblica da homérica em seu ensaio antológico "A cicatriz de Ulisses"23. Para captar os diversos níveis "verticais" de sentido, o pensamento e a escrita que procura expor esse pensamento não podem fluir de forma contínua, mas devem passar por interrupções. Sem dúvida, Benjamin não podia reproduzir em seu trabalho acadêmico as interrupções que são visíveis na versão manuscrita do texto. Para produzir, ainda assim, o "ritmo intermitente" da própria escrita, ele era obrigado a se servir de recursos sintáticos, substituindo a concatenação hipotática e seus conectores pela justaposição paratática, uma distinção que Adorno considerou como fundamental em sua leitura de Hölderlin. ${ }^{24}$

Benjamin, portanto, não apenas ignora, até certo grau, a mediação conceitual e, assim, a discussão acadêmica do seu tempo, da qual, como no caso da fenomenologia sobraram apenas alguns traços no "Prefácio", mas também a mediação sintática em função de uma síntese lógica. Há outra grande ironia no fato de que Adorno, em "O ensaio como forma", apresenta o amigo como "mestre inalcançável" 25 (unerreichten Meister ${ }^{26}$ ) no gênero. Neste ensaio também, Adorno faz referência ao "Prefácio", adotando expressões usadas por Benjamin como, por exemplo, aquela da "coerência dedutiva"27, uma tradução simplificada de lückenloser Deduktionszusammenhang ${ }^{28}$, um "monstro" lexical cuja tradução literal seria algo como "nexo dedutivo sem lacunas". Mas é o próprio caráter bizarro da expressão que faz com que seu uso remeta imediatamente a um texto anterior desde que o leitor tenha conhecimento deste último. A "presença de espírito" que Benjamin cobra do historiador materialista nas Passagens ${ }^{29}$ também se espera do leitor dos seus escritos para que o efeito de uma citação se realize e para que se estabeleça uma relação entre dois textos distantes, evidenciando que o ensaio cumpra os postulados feitos no "Prefácio". Se uma das dificuldades dos textos de Benjamin consiste no fato de ele restringir o significado de palavras da linguagem comum, tais como Darstellung e Erfahrung, a um uso específico, sem justificar essa restrição através de uma definição adequada, há, por outro lado, uma série de expressões e construções verbais criadas por ele que, como no caso da "coerência dedutiva", remetem imediatamente aos seus textos pela raridade da expressão, como no caso de lückenloser Deduktionszusammenhang. É essa raridade que faz com que o leitor assíduo de Benjamin se lembre imediatamente do seu uso em outros textos, conforme os mecanismos da "memória involuntária" de Proust. A relação entre a ocorrência presente de uma expressão e sua ocorrência no passado não se deve,

Cadernos Benjaminianos, Número especial, Belo Horizonte, 2013, página 89-99 
portanto, a um esforço consciente ou voluntário, mas é provocado simplesmente pela repetição material do significante.

Em seu prefácio ao primeiro volume das Obras Escolhidas de Benjamin, J. M. Gagnebin destaca a importância de Proust nas chamadas "Teses", intituladas "Sobre o conceito de história" ${ }^{30}$, e o fenômeno da citação baseada no que ela denomina, de forma muito acertada, a "presença do passado no presente" 31 . A madeleine proustiana é capaz de evocar a infância do protagonista, enquanto o passado individual, está presente, mesmo de forma latente. Para Benjamin, o mesmo vale para a história, pois o passado continua presente. E, se a moda, enquanto fenômeno estético, é capaz de citar esse passado latente, essa capacidade se deve, mais uma vez, à singularidade de algum acessório. É a raridade e a peculiaridade do objeto que desencadeia a memória involuntária, sendo que essa peculiaridade não precisa ser uma característica do objeto, mas pode resultar da combinação inusitada de dois ou mais objetos e sua percepção sensorial. Assim, não é a madeleine que faz surgir a infância do protagonista proustiano, mas o gosto gerado pela combinação rara desse biscoito quando molhado no chá de tílias, uma combinação que o protagonista não chegou a provar durante décadas e que só assim foi capaz de evocar a infância: "Para que um fragmento do passado seja tocado pela atualidade não pode haver qualquer continuidade entre eles". ${ }^{32}$

O caso das palavras não é diferente: basta que palavras comuns sejam empregadas numa combinação - ou numa "constelação", como diria Benjamin - rara como aquela do "nexo dedutivo sem lacunas" - para que produzam o "efeito-madeleine". O que importa é "sentir o gosto da palavra", isto é, a percepção sensorial, seja visual, seja auditiva, do significante, e não aquilo que ela representa em sua relação arbitrária com algum significado. Em seu uso "expositivo", no sentido da Darstellung, a palavra perde seu caráter meramente representativo para ganhar um caráter de objeto, isto é, algo perceptível pelos sentidos, ao ponto em que a distinção entre as palavras e as coisas se torne obsoleta.

Uma das proximidades entre Benjamin e a psicanálise, apontadas por Sigrid Weigel no referido texto, é justamente a importância da palavra como significante, que, via associação, pode "citar" contextos distantes do contexto presente, apontando, ao mesmo tempo, para a "presença do passado no presente", para retomar a fórmula de J. M. Gagnebin. Em oposição ao conceito pretensamente universal, a "constelação" verbal singular - segundo o "Prefácio", toda constelação é singular - permite estabelecer uma relação particular, capaz de "salvar os fenômenos", ao invés de aniquilá-los. Infelizmente, a tradução brasileira não reproduz a expressão crucial de das Einmalig-Extreme ${ }^{33}$, "o singular-extremo", que expressa a singularidade através de um termo raro e singular - e ainda pode servir, ele mesmo, como exemplo da Darstellung, da exposição de uma ideia. Cabe lembrar que a constelação, em Benjamin (e, posteriormente, também em Adorno), não é uma configuração qualquer (conforme seu uso universalizante), mas que, para Benjamin, se trata mesmo de uma "imagem-de-estrelas", de um Sternbild, que, além de ser uma imagem (Bild) e de ter, assim, um caráter "expositivo", possui uma forma bizarra, ou seja, singular.

Basicamente, qualquer citação é feita mediante a repetição. Mas, devido ao caráter metonímico do elemento repetido, a citação não apenas repete uma palavra ou uma impressão sensorial como no caso da madeleine -, mas evoca concomitantemente o contexto associado. A repetição do mesmo evoca outro, motivo pelo qual a citação verbal, seja através da repetição de uma única palavra,

Cadernos Benjaminianos, Número especial, Belo Horizonte, 2013, página 89-99 
quando possui uma "carga" metonímica, ocasiona a interrupção da progressão linear do texto em que é usada. O déjà-vu, evocado por uma única palavra, provoca uma cesura que, pela sua própria unicidade, corta o continuum do texto - para citar o termo em latim, isto é, para citar o mesmo uso feito na tradução brasileira das "Teses", associando, assim, de forma imediata - ou não-mediada - a questão do texto àquela da história.

É mérito de J. M. Gagnebin ter elaborado a complexidade dessa relação em seu livro História e narração em Walter Benjamin, sendo que um dos principais elementos que permitem a aproximação entre a história e o texto narrativo é a citação. Normalmente entendida como um fenômeno textual, baseado na repetição literal da parte de um texto, Benjamin desenvolve para a história a citação lato sensu no sentido da Jetztzeit, do tempo de agora, no qual determinado presente "cita" o passado com base na repetição de um evento muitas vezes tido como banal, como no episódio da madeleine de Proust. O caráter cotidiano desse episódio, no entanto, não impede que ele seja, ao mesmo tempo, singular, sendo que esta qualidade garante, paradoxalmente, a possibilidade de ele se revelar como fundamental na superação de grandes distâncias temporais e de perder, assim, sua banalidade.

Daí a importância do cronista da $3^{\mathrm{a}}$ tese não dever distinguir entre os acontecimentos grandes e pequenos, ${ }^{34}$ pois os pequenos guardam em si o potencial de se tornarem grandes - basta que se repitam. Se a própria repetição tem um aspecto banal, ela alcança uma dimensão superior quando acontece na qualidade de uma citação, ou seja, quando o elemento repetido traz consigo um passado aparentemente morto. Muitas vezes, a Darstellung também tem esse aspecto banal, porque se limita simplesmente a "despertar" um passado que está "dormindo", para retomar o Leitmotiv das Passagens, essa obra que também "expõe" fragmento por fragmento, muitos deles citações dos mais diversos contextos. Mas a "positividade" dessa exposição nada tem de positivista, pois cada fragmento possui o potencial de se associar a outro fragmento distante, potencial este que o próprio autor sinaliza quando acrescenta uma palavra-chave a alguns fragmentos das Passagens, uma espécie de hyperlink que, em sua qualidade de "micro-citação", permite as mais diversas aproximações mútuas. A exposição dos fragmentos enquanto Darstellung dispensa a mediação pelo conceito, isto é, por uma terceira instância que pretende reunir fenômenos particulares sob o comando de uma mediação universal, possibilitando assim o jogo livre das citações.

Sem dúvida, a leitura dos textos benjaminianos causa uma série de dificuldades e exige do leitor, de acordo com os postulados do "Prefácio", um procedimento circular, semelhante ao "círculo hermenêutico" de Gadamer ${ }^{35}$ : "Incansavelmente, o pensamento começa sempre de novo, e volta sempre, minuciosamente, às próprias coisas." 36 Não há dúvida, também, que Benjamin, quando defende a Darstellung como questão fundamental do discurso filosófico, advoga em causa própria. No entanto, esse discurso "expositivo" não é o capricho de um autor um tanto extravagante, porém provoca o questionamento do discurso em vigor e sua pretensão à universalidade dos seus conceitos. O idioleto de Benjamin é apenas uma forma "singular-extrema" de escrita que procura deixar claro que toda escrita, mesmo recorrendo a conceitos supostamente universais, acaba desenvolvendo significados específicos e idiossincráticos, escondendo, porém, as suas particularidades sob uma pretensa universalidade. É mérito de Benjamin ter explicitado o aspecto "expositivo", a saber, estético do texto filosófico, desmascarando, assim, as pretensões a um discurso supostamente neutro.

Cadernos Benjaminianos, Número especial, Belo Horizonte, 2013, página 89-99 
Resumé: Quand Benjamin, dans la première phrase de son Origine $d u$ drame baroque, attribue um lieu central à la Darstellung (au sens de «présentation »), il s'éloigne du discours académique traditionel, basé sur l'usage systématique du concept et son rôle médiateur. Em partant de la critique de Jeanne Marie Gagnebin de la traduction de Darstellung comme « représentation» et des objections de Adorno, nous cherchons à développer une distinction de base entre la médiation (Vermittlung) et la présentation (Darstellung) en tant que deux options du discours philosophique.

Keywords: médiation; présentation; représentation.

\section{Referências Bibliográficas}

ADORNO, Theodor W. "Der Essay als Form". In: Theodor W. Adorno. Noten zur Literatur. Frankfurt/M.: Suhrkamp, 1981, p. 9-33.

ADORNO. "Parataxis: Zur späten Lyrik Hölderlins". Noten zur Literatur. Frankfurt/M.: Suhrkamp, 1974, p. 447-491.

ADORNO, Theodor W. Parataxis - a lírica tardia de Hölderlin. In: _. Notas de literatura. Trad. Celeste Aída Galeão e Idalina Azevedo da Silva. Rio de Janeiro: Tempo Brasileiro, 1973, p. 73-122. (Coleção biblioteca tempo universitário, n. 36)

ADORNO. Notas de literatura. Trad. Jorge de Almeida. São Paulo: Duas Cidades; Editora 34, v. 1, 2003.

ADORNO. "O ensaio como forma." In: Theodor W. Adorno. Notas de literatura. Trad. Jorge de Almeida. São Paulo: Duas Cidades; Editora 34, v1, 2003, p. 15-45.

ARENDT, Hannah. Homens em tempos sombrios. São Paulo: Companhia das Letras, 1987.

AUERBACH, Erich. "A cicatriz de Ulisses”. Mimesis: a representação da realidade na literatura ocidental. São Paulo: Perspectiva, 2007, p. 1-20.

BENJAMIN, Walter. Gesammelte Schriften. Rolf Tiedemann, Hermann Schweppenhäuser (orgs.). Vols. I-VII. 1 ${ }^{a}$ ed., Frankfurt/M.: Suhrkamp, 1972-1999.

BENJAMIN, Walter. Origem do drama barroco alemão. Tradução, apresentação e notas: Sérgio Paulo Rouanet. São Paulo: Brasiliense, 1984.

Cadernos Benjaminianos, Número especial, Belo Horizonte, 2013, página 89-99 
BENJAMIN, Walter. Briefe. Gershom Scholem, Theodor W. Adorno (orgs.). 2 vols. Frankfurt/M.: Suhrkamp, 1966.

BENJAMIN, Walter. Charles Baudelaire - um lírico no auge do capitalismo. São Paulo: Brasiliense, 1989. Obras escolhidas, Vol. III.

BENJAMIN, Walter. Magia e Técnica, Arte e Política. Trad. Paulo Sérgio Rouanet. São Paulo: Brasiliense, 1985. Obras escolhidas, Vol. I.

BENJAMIN, Walter. Passagens. Organização Willi Bolle; colaboração na organização Olgária Chain Féres Matos; tradução do alemão Irene Aron; tradução do francês Cleonice Paes Barreto Mourão. Belo Horizonte: Editora UFMG; São Paulo: Imprensa Oficial do Estado de São Paulo, 2006.

BENJAMIN, Walter. "Sobre o conceito de história". Magia e Técnica, Arte e Política. Trad. Paulo Sérgio Rouanet. São Paulo: Brasiliense, 1985, p. 222-232.

BENJAMINS BEGRIFFE. Michael Opitz, Erdmut Wizisla (orgs.). Frankfurt/M.: Suhrkamp, 2000.

GADAMER, Hans-Georg. Wahrheit und Methode. $3^{\mathrm{a}}$ ed., Tübingen, 1975.

GAGNEBIN, Jeanne Marie. "Do conceito de Darstellung em Walter Benjamin ou verdade e beleza". Kriterion, 46, 2005, 183-190.

GAGNEBIN, Jeanne Marie. História e narração em Walter Benjamin. $2^{\mathrm{a}}$ ed. São Paulo: Perspectiva, 1999.

GAGNEBIN, Jeanne Marie. "Walter Benjamin ou a história aberta”. Magia e Técnica, Arte e Política. Trad. Paulo Sérgio Rouanet. São Paulo: Brasiliense, 1985. Obras escolhidas. Vol. I. p. 7-19.

WEIGEL, Sigrid. Entstellte Ähnlichkeit. Frankfurt/M.: Fischer, 1997.

\section{Notas}

${ }^{1}$ BENJAMIN, Origem do drama barroco alemão.

${ }^{2}$ GAGNEBIN, "Do conceito de Darstellung".

${ }^{3}$ GS, I, p. 207; trad. modificada de Sérgio Paulo Rouanet (cf. Benjamin, Origem do drama alemão, p. 49); daqui por diante, as referências à edição alemã dos "Escritos reunidos" (Gesammelte Schriften) de Benjamin serão feitas por meio da sigla "GS", que se tornou convencional entre os comentadores da obra de Benjamin. Quanto à tradução do termo Darstellung, daremos preferência uma das duas sugestões de tradução de J. M. Gagnebin no referido artigo, a saber, "exposição".

${ }^{4}$ Essa diferenciação coincide com aquela entre estilo paratático e hipotático, feita por Adorno no ensaio "Parataxis: Zur späten Lyrik Hölderlins", um dos vários ensaios de inspiração benjaminiana.

${ }^{5}$ BENJAMIN, Origem do drama barroco alemão, p. 50. 
${ }^{6}$ GAGNEBIN, "Do conceito de Darstellung", 184-185.

${ }^{7}$ BENJAMIN, Passagens, fragmento N 7, 7, p. 502.

${ }^{8}$ Refiro-me à publicação alemã Benjamins Begriffe (cf. Bibliografia).

${ }^{9}$ WEIGEL, Entstellte Ähnlichkeit, p. 36.

${ }^{10}$ Cf. a carta de Adorno a Benjamin de 10/11/1938 em BENJAMIN, Briefe, p. 782-789.

${ }^{11}$ BENJAMIN, Briefe, p. 782-789; grifo de Adorno. Cabe observar que Hannah Arendt, apesar de também ter notado esse uso peculiar dos conceitos marxistas por Benjamin, não se incomodava com ele, mas o considerou como característica de um filósofo que pensava "poeticamente" (ARENDT, Homens em tempos sombrios, p. 144)

${ }_{12}$ Cf. a carta de 19/2/1940, GS, I, p. 1130.

${ }^{13}$ BENJAMIN, Charles Baudelaire - um lírico no auge do capitalismo.

${ }^{14}$ BENJAMIN, GS, I, p. 1130.

${ }^{15}$ BENJAMIN, Origem do drama barroco alemão, p. 67.

${ }^{16}$ BENJAMIN, GS, I, p. 225.

${ }^{17}$ BENJAMIN, GS, I, p. 228.

${ }^{18}$ BENJAMIN, Origem do drama barroco alemão, p. 70.

${ }^{19}$ BENJAMIN, Origem do drama barroco alemão, p. 56.

${ }^{20}$ BENJAMIN, ibid.

${ }^{21}$ BENJAMIN, GS, I, p. 214.

${ }^{22}$ BENJAMIN, Origem do drama barroco alemão, p. 51.

${ }^{23}$ AUERBACH, "A cicatriz de Ulisses".

${ }^{24}$ Cf. nota 4.

${ }^{25}$ ADORNO, "O ensaio como forma", p. 20.

${ }^{26}$ ADORNO, "Der Essay als Form", p. 20.

${ }^{27}$ BENJAMIN, Origem do drama barroco alemão, p. 55.

${ }^{28}$ BENJAMIN, GS, I, p. 213.

${ }^{29}$ BENJAMIN, Passagens, fragmento N 7, 2, p. 511.

${ }^{30}$ BENJAMIN, "Sobre o conceito de história".

${ }^{31}$ BENJAMIN, "Walter Benjamin ou a história aberta", p. 15.

${ }^{32}$ BENJAMIN, Passagens, fragmento N 7, 7, p. 512.

${ }^{33}$ BENJAMIN, GS, I, p. 215.

${ }^{34}$ BENJAMIN, "Sobre o conceito de história", p. 223.

${ }^{35}$ GADAMER, Wahrheit und Methode, p. 275.

${ }^{36}$ BENJAMIN, Origem do drama barroco alemão, p. 50. 